\title{
PERAN MEDIASI PEMBERDAYAAN PADA PENGARUH STRES KERJA DAN KONFLIK PEKERJAAN-KELUARGA TERHADAP KOMITMEN PROFESIONAL
}

\author{
I Gst Ngr Bgs Bimantara Kepakisan ${ }^{1}$ \\ Wayan Gede Supartha ${ }^{2}$ \\ I Gusti Ayu Manuati Dewi ${ }^{3}$
}

\author{
${ }^{1}$ Fakultas Ekonomi dan Bisnis Universitas Udayana (Unud), Bali, Indonesia \\ email: bimantarakepakisan@yahoo.com \\ ${ }^{2}$ Fakultas Ekonomi dan Bisnis Universitas Udayana (Unud), Bali, Indonesia
}

\begin{abstract}
ABSTRAK
Penelitian ini bertujuan untuk menguji peran pemberdayaan dalam memediasi pengaruh stres kerjadan konflik pekerjaan-keluarga terhadap komitmen profesional karyawan di PT. Bhineka Putra Perkasa. Penelitian ini dilakukan di PT. Bhineka Putra Perkasa yang berlokasi di Denpasar. Jumlah sampel 52 responden dengan mengunakan metode sensus. Data diuji menggunakan teknik analisis path. Hasil analisis menunjukkan bahwa stres kerja berpengaruh negatif terhadap pemberdayaan. Konflik pekerjaan-keluarga berpengaruh negatif terhadap pemberdayaan, stres kerja berpengaruh negatif terhadap komitmen profesional karyawan dan konflik pekerjaan-keluarga berpengaruh negatif terhadap komitmen profesional karyawan. Pemberdayaan berpengaruh positif terhadap komitmen profesional karyawan. Pemberdayaan memediasi pengaruh stres kerja terhadap komitmen profesional karyawan dan memediasi pengaruh konflik pekerjaan-keluarga terhadap komitmen profesional karyawan. Saran bagi pihak perusahaan yang direkomendasikan agar bertindak dengan integritas, melalui konsistensi dengan memilih dan menempatkan karyawannya disesuaikan dengan kemampuan yang dimilikinya untuk menghindari konflik kerja. Bertindak tegas dalam membina karyawan sehingga mempunyai rasa kerjasama yang baik untuk menurunkan tingkat stress dalam bekerja.
\end{abstract}

Kata kunci: stres kerja, konflik pekerjaan-keluarga, pemberdayaan, komitmen profesional

\begin{abstract}
This study aims to examine the role of empowerment in mediating the influence of work stress and work-family conflict to professional commitment of employees at PT. Bhineka Putra Perkasa. This research was conducted at PT. Bhineka Putra Perkasa located on Denpasar. The number of samples was 52 respondents taken using slovin method. Data were tested using path analysis techniques. The result of the analysis shows that job stress has negative effect on empowerment. Work-family conflicts negatively affect empowerment, job stress negatively affects employee professional commitment and work-family conflicts negatively affect employees' professional commitments. Empowerment positively affects employees' professional commitment. Empowerment mediates the effect of job stress on employee professional commitment and mediates the impact of work-family conflicts on employee professional commitments. Suggestions for recommended companies are required to act with integrity, through consistency by choosing and placing employees according to their ability and knowledge to avoid work conflicts. Acting firmly in fostering employees so as to have a good sense of cooperation to reduce stress levels in work
\end{abstract}

Keywords: job stress, work-family conflict, empowerment, professional commitment 


\section{PENDAHULUAN}

Pembinaan, pengarahan, dan pengembangan komitmen profesional dari sumber daya manusia sangat diperlukan demi kelancaran proses kegiatan dalam suatu organisasi atau perusahaan. Setiap perusahaan dalam melakukan aktivitasnya hendaknya memperhatikan komitmen profesional karyawannya, karena karyawan yang memiliki komitmen profesional adalah modal utama karyawan dalam merencanakan, menganalisis, mengarahkan serta menggerakkan faktor-faktor yang ada dalam suatu organisasi secara maksimal (Siwi, 2005). Dalam menjalani kehidupan yang serba modern ini, seorang karyawan dituntut untuk bekerja dengan mental baja, sehingga tidak takut terhadap tuntutan kerja yang menimbulkan stres kerja atau kelelahan kerja, dengan itu karyawan bisa menikmati segala tekanan kerja sesuai tuntutan perusahaan (Fereshti \& Fatkhurohman, 2012).

PT. Bhineka Putra Perkasa sebagai perusahaan yang bergerak dibidang industri pengolahan segala jenis kopi di Provinsi Bali dengan tuntutan kerja yang cukup tinggi harus mampu dalam memelihara sikap komitmen profesional karyawan dalam bekerja sehingga mampu meningkatkan kinerja perusahaan. Organisasi atau perusahaan memiliki peran krusial dalam membantu karyawan membangun komitmen professional. Rivai (2006: 261) menyatakan komitmen profesional dipandang sebagai kesuksesan seseorang dalam suatu pekerjaan yang digelutinya.

Terdapat beberapa indikasi masalah komitmen profesional karyawan pada PT. Bhineka Putra Perkasa berdasasarkan wawancara dengan 35 karyawan selama tiga 
hari. Pihak yang diwawancarai adalah operasional manager, personalia, staf kantor dan staf pabrik serta satpam. Masalah yang sering dialami karyawan terkait komitmen professional adalah masalah pengabdian mereka yang sering dirasakan staf kantor dan staf pabrik yang merasa tidak akan berkembang dan maju dari segi profesi. Berbagai peran yang harus dipenuhi karyawan secara tidak langsung rentan memicu terjadi stres kerja pada diri karyawan (Fereshti \& Fatkhurohman, 2012).

Stres kerja berperan sebagai kejadian simultan dari dua atau lebih bentuk tekanan pada tempat kerja, dimana pemenuhan dari satu peran membuat pemenuhan terhadap peran tersebut yang lebih sulit untuk dilaksanakan (Yustrianthe, 2008). Artinya apabila karyawan mengalami stres ditempat kerja, di saat itu seseorang karyawan dalam melaksanakan satu peran tertentu akan merasa kesulitan untuk memenuhi harapan peran tersebut dengan tekanan kerja yang berlebihan (Jawwad and Hussain, 2012).

Terlepas dari itu sikap karyawan yang mengalami stres kerja pada pekerjaan yang dapat memicu terjadi konflik pekerjaan-keluarga pada diri karyawan (Rantika, 2010). Konflik pekerjaan-keluarga merupakan faktor yang dapat menentukan komitmen karyawan dalam bekerja (Laeeque, 2014). Pekerjaan dan keluarga merupakan dua domain utama dalam kehidupan orang dewasa yang bekerja (Febrianty, 2012). Akintayo (2010) menyatakan peran aktif dalam keduanya menyebabkan mereka mempunyai peran ganda, peran dalam pekerjaan (sebagai pekerja) dan juga peran dalam keluarga (sebagai istri, suami, dan orangtua). 
Hasil wawancara yang dilakukan berdasarkan job description khususnya pada bagian stok, staf kantor dan pabrik yang memiliki jadwal yang padat hingga larut malam karena mengepak barang yang akan dikirim keluar Negeri maupun dalam Negeri mengingat permintaan yang banyak, datangnya kunjungan tamu seperti wisatawan Korea selatan ataupun korea utara, Amerika Serikat dan Prancis yang padat hingga larut malam. Hal-hal semacam ini yang membuat setiap karyawan merasa terbebani dan timbulnya masalah konflik pekerjaan-keluarga.

Faktor yang dapat membangun komitmen profesional karyawan adalah pemberdayaan (Febrianty, 2012). Pemberdayaan adalah pemberian wewenang kepada karyawan untuk merencanakan (planning), mengendalikan (controlling) dan membuat keputusan atas pekerjaan yang menjadi tanggung jawabnya tanpa harus mendapatkan otorisasi secara eksplisit dari atasannya. Karyawan akan mengeluarkan semua potensi yang ada dalam dirinya melalui pemberdayaan, sehingga meningkatkan komitmen profesionalnya terhadap perusahaan (Shakeel et al., 2012).

Melalui pemaparan masalah yang telah dijabarkan, maka tujuan penelitian ini adalah 1) Untuk mengetahui pengaruh stres kerja terhadap pemberdayaan karyawan, 2) Untuk mengetahui pengaruh konflik pekerjaan-keluarga terhadap pemberdayaan karyawan, 3) Untuk mengetahui pengaruh stres kerja terhadap komitmen profesional karyawan. 4) Untuk mengetahui pengaruh konflik pekerjaan-keluarga terhadap komitmen profesional karyawan. 5) Untuk mengetahui pengaruh pemberdayaan terhadap komitmen profesional karyawan. 6) Untuk mengetahui peran mediasi 
pemberdayaan atas pengaruh stres kerja terhadap komitmen profesional karyawan. 7) Untuk mengetahui peran mediasi pemberdayaan atas pengaruh konflik pekerjaankeluarga terhadap komitmen profesional karyawan.

\section{Komitmen Profesional}

Komitmen profesional mengacu pada kekuatan identifikasi individual dengan profesi. Individual dengan komitmen profesional yang tinggi dicirikan memiliki kepercayaan dan penerimaan yang tinggi sebagai tujuan profesinya di perusahaan, keinginan untuk berusaha sekuatnya atas nama profesi, dan keinginan yang kuat untuk mempertahankan keanggotaannya dalam profesi di perusahaan (Murtiasri, 2006).

Indikator Komitmen Profesional

Para tenaga profesional biasanya telah dididik untuk menjalankan tugas-tugas yang komplek secara independen dan memecahkan permasalahan yang timbul dalam pelaksanaan tugas-tugas dengan menggunakan keahlian dan dedikasi secara professional (Schwartz, 1996) dalam Badjuri (2009). Menurut Hall, dalam Badjuri (2009) terdapat lima indikator komitmen profesional, yaitu: 1) Pengabdian pada profesi, 2) Kewajiban sosial, 3) Kemandirian, 4) Keyakinan terhadap peraturan profesi, dan 5) Hubungan dengan sesama profesi. 
Pemberdayaan

Robbins (2008:29) menyatakan pemberdayaan merupakan menempatkan pekerja yang bertanggung jawab atas apa yang mereka kerjakan. Memberdayakan orang berarti mendorong mereka menjadi lebih terlibat dalam keputusan dan aktivitas yang mempengaruhi pekerjaan mereka. Konsep Thomas dan Velthouse (1990) sebagai berikut: 1) Sense of meaning, merupakan nilai tujuan pekerjaan yang dilihat dari hubungannya pada idealisme atau standar individu. 2) Sense of competence, merupakan kepercayaan individu akan kemampuan mereka dalam melakukan aktivitas mereka dengan menggunakan keahlian yang mereka miliki. 3) Sense of selfdetermination, merupakan suatu perasaan memiliki suatu pilihan dalam membuat pilihan dan melakukan suatu pekerjaan. 4) Sense of impact, merupakan derajat dimana seseorang dapat mempengaruhi hasil pekerjaan baik strategik, administratif, ,maupun operasional.

Indikator Pemberdayaan

Indikator yang dinilai mengacu pada penelitian Nur (2008) adalah sebagai berikut. 1) Pemberian kesempatan pekerjaan yang sesuai dengan keinginan individu. 2) Memberikan kesempatan pekerjaan yang sangat berarti bagi individu. 3) Memberikan kesempatan pekerjaan bagi individu yang terbaik untuk perusahaan. 4) Memberikan ketepatan penempatan bagi individu sesuai dengan rekan kerja. 5) 
Memberikan ketepatan pekerjaan sesuai kemampuan individu dalam melakukan pekerjaan apapun

\section{Stres Kerja}

Kreitner dan Kinicki (2005:351) mendefinisikan stres kerja sebagai respon adaptif yang dihubungkan oleh karaktersitik atau melalui proses psikologis individu, yang merupakan suatu konsekuensi dari setiap tindakan eksternal, situasi, atau peristiwa yang menempatkan tuntutan psikologis/fisik khusus pada seseorang. Mangkunegara (2011:28) menyatakan bahwa stres kerja adalah perasaan yang menekan atau merasa tertekan yang dialami seseorang dalam menghadapi pekerjaan. Indikator Stres Kerja

Adapun indikator yang dipakai untuk mengukur stres kerja mengacu pada (Timangratuogi, 2012) adalah sebagai berikut. 1) Tugas, tugas dengan sasaran pekerjaan yang tidak jelas. 2) Hasil kerja, pelaporan hasil pekerjaan karyawan yang tidak jelas harus ditujukan pada siapa. 3) Rekan kerja, karyawan tidak saling mendukung dalam menjalankan pekerjaan. 4) Peraturan, yang diterapkan perusahaan menyulitkan karyawan dalam bekerja.

\section{Konflik Pekerjaan-keluarga (Work Family Conflict)}

Marquise dan Huston (dalam Febrianty, 2012) mendefinisikan konflik sebagai masalah internal dan eksternal yang terjadi sebagai akibat dari perbedaan pendapat, 
nilai-nilai, keyakinan dari dua orangatau lebih. Menurut Littlefield (dalam Rantika, 2010) bahwa konflik dapat dikategorikan sebagai suatu kejadian atau proses. Sebagai kejadian, konflik terjadi dari suatu ketidaksetujuan antara dua atau orang atau organisasi, dimana orang tersebut menerima sesuatu yang akan mengancam kepentingannya.

Indikator Konflik Pekerjaan-keluarga (Work Family Conflict)

Febrianty (2012) menjelaskan indikator yang digunakan untuk mengukur Konflik Pekerjaan-keluarga (Work Family Conflict) yaitu: 1) Time Based Conflict, kurangnya aktivitas bersama keluarga. 2) Strain Based Conflict, mengabaikan kehidupan rumah tangga. 3) Behavior Based Conflict, sulit untuk memenuhi tanggung jawab keluarga.

Teori Pendukung (The Three-component Model of Organisational Commitment)

Meyer dan Allen (1997:98) menganalisis sejumlah model komitmen satu dimensi dari komitmen organisasi untuk mendeteksi berbagai faktor yang berkaitan dengan munculnya fenomena ini dalam teori yang berbeda. Tiga jenis komitmen berikut muncul di sebagian besar studi yang mereka lihat: komitmen berdasarkan emosi, komitmen berdasarkan perhitungan biaya, dan komitmen berdasarkan kewajiban. 
Kerangka Konseptual

Komitmen profesional dapat didefinisikan sebagai berikut (1) Sebuah kepercayaan pada dan penerimaan terhadap tujuan-tujuan dan nilai-nilai dari profesi, (2) Sebuah kemauan untuk menggunakan usaha yang sungguh-sungguh guna kepentingan profesi, (3) sebuah keinginan untuk memelihara keanggotaan dalam profesi (Khattak et al, 2013).

Pemberdayaan merupakan wewenang untuk membuat keputusan dalam suatu area kegiatan operasi tertentu tanpa harus memperoleh pengesahan orang lain (Luthans, 2011). Penelitian Churiyah (2011) mengemukakan pemberdayaan diukur melalui dimensi pemberian tanggungjawab dan wewenang, serta hubungan personel dengan indikator sebagai berikut: kesesuaian tanggungjawab dengan kompetensi awak kapal, kesesuaian pekerjaan dengan keahlian karyawan, ketepatan pengawasan pada karyawan, kepercayaan manajemen terhadap karyawan, keeratan hubungan kerja antara manajemen dengan karyawan, dan ketepatan pembinaan karyawan. Penelitian Khattak et al (2013) mengindikasikan bahwa terjadinya stres kerja berhubungan dengan tingginya tingkat konflik pekerja keluarga yang dalam halini tidak hanya dialami oleh wanita tetapi juga oleh pria, di mana tingkat konflik pekerjaan - keluarga mempunyai dampak negatif pada professional komitmen. Semakin tinggi tingkat konflik pekerja keluarga maka semakin rendah profesional komitmen karyawan. Kerangka konseptual dari penelitian ini dapat dilihat pada Gambar 1. 


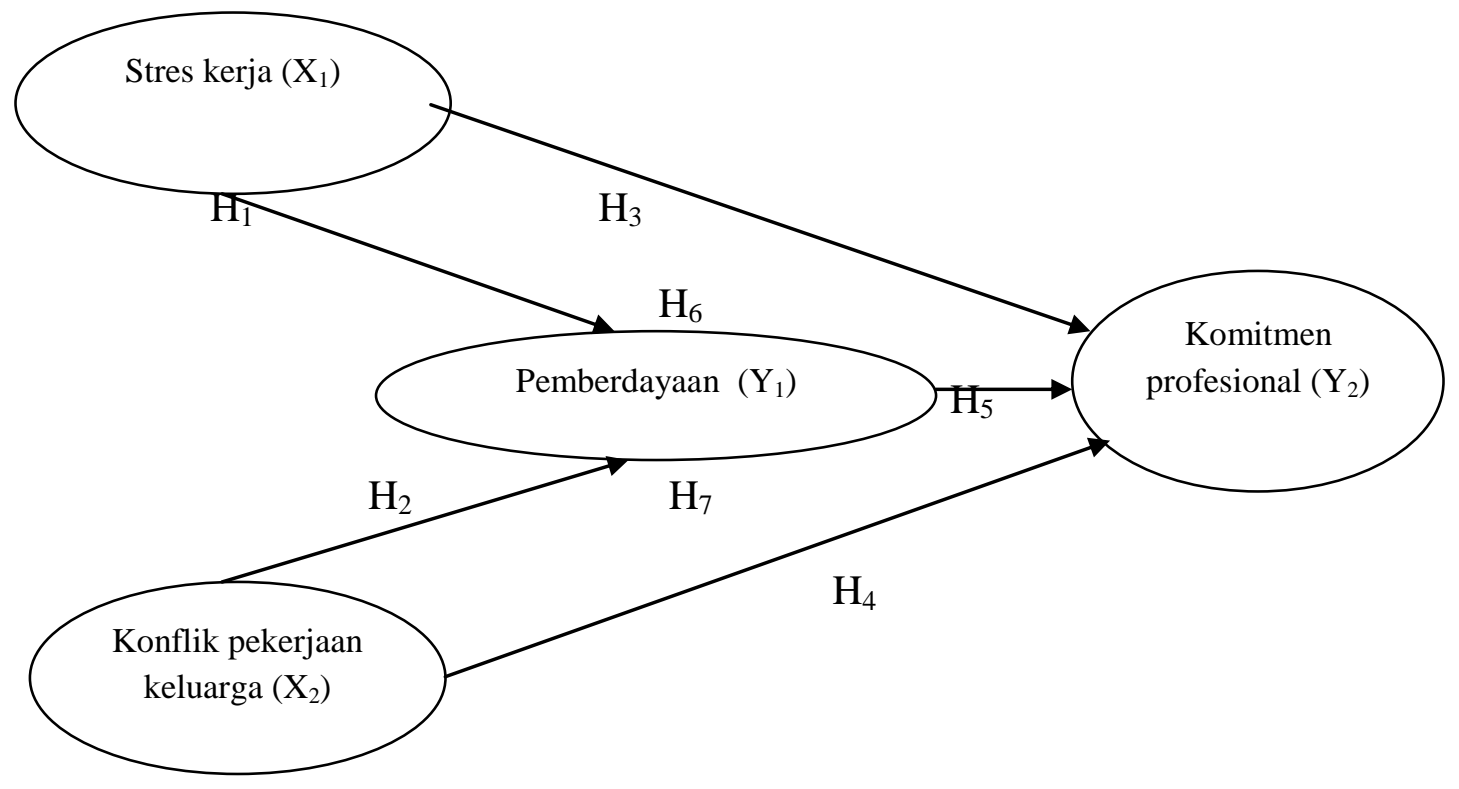

\section{Gambar 1. Kerangka Konseptual Penelitian}

Orang bekerja dan melakukan tugas serta bertanggungjawab pada pekerjaannya, sering dipengaruhi oleh tingkat stres kerja yang dirasakan (Popov et al., 2013). Yusuf (2013) menyatakan bahwa stres kerja yang dialami oleh seorang akan memberikan dampak negatif pada pemberdayaan dalam perusahaan yang memunculkan sikap stres kerja yang berpotensi menimbulkan tindakan yang tidak professional dalam melaksanakan pekerjaan. Berdasarkan hasil penelitian tersebut maka dapat dirumuskan hipotesis penelitian sebagai berikut:

\section{$\mathrm{H}_{1}$ : Stres kerja berpengaruh negatif terhadap pemberdayaan}

Pada sebuah perusahaan kesuksesan atau kegagalan dalam pelaksanaan tugas dan penyelenggaraan, dipengaruhi oleh tingkat konflik pekerjaan-keluarga yang 
terjadi, konflik pekerjaan-keluarga mampu menurunkan daya ingat karyawan sehingga memiliki dampak negatif terhadap pemberdayaan (Ozbag dan Ceyhun, 2014). Jawwad and Hussain (2012) meneliti mengenai pengaruh konflik pekerjaankeluarga terhadap stres kerja yang berasal dari pasangan hidup dan keluarga, rekan kerja dan atasan dimoderasi oleh variabel pemberdayaan yang memberikan pengaruh negatif. Berdasarkan hasil penelitian tersebut maka dapat dirumuskan hipotesis penelitian sebagai berikut :

\section{$\mathrm{H}_{2}$ : Konflik pekerjaan-keluarga berpengaruh negatif terhadap pemberdayaan}

Khatibi dan Hamidi (2009) menyatakan stres kerja yang dialami karyawan juga harus atasi, karena memberikan pengaruh negatif terhadap intensitas komitmen profesional. Febrianty (2012) berpendapat adanya pengaruh negatif stres kerja kerja terhadap komitmen profesional yang sangat berpengaruh terhadap kelangsungan organisasi. Jawwad and Hussain (2012) mengemukakan stres kerja memiliki pengaruh yang signifikan dan negatif terhadap komitmen profesional karyawan. Berdasarkan hasil penelitian yang telah disebutkan diatas, maka dapat dirumuskan hipotesis sebagai berikut :

\section{$\mathrm{H}_{3}$ : Stres kerja berpengaruh negatif terhadap komitmen professional}

Konflik pekerjaan-keluarga yang dialami oleh karyawan memicu terjadinya penurunan pada sikap komitmen profesional karyawan dalam bekerja. Bragger et al. 
(2013) menyatakan konflik pekerjaan-keluarga memberikan dampak negatif terhadap sikap komitmen profesional setiap karyawan dalam melaksanakan tugas dan tanggung jawabnya. Hasil penelitian Akintayo (2010) menunjukkan bahwa konflik pekerjaan-keluarga berdampak signifikan negatif terhadap komitmen profesional karyawan. Berdasarkan hasil penelitian yang telah disebutkan diatas, maka dapat dirumuskan hipotesis sebagai berikut:

\section{$H_{4}$ : Konflik pekerjaan-keluarga berpengaruh negatif terhadap komitmen professional}

Melakukan pemberdayaan menjadi suatu pekerjaan bagi manajemen agar terus berupaya menjaga kelangsungan perusahaan dengan turut serta memotivasi karyawan yang memberikan pengaruh positif pada komitmen profesional karyawan dalam bekerja (Churiyah, 2011). Hasil penelitian Yusuf (2013) membuktikan terdapat hubungan antara pemberdayaan dengan komitmen profesional dalam bekerja. Begitu pula peneitian yang dilakukan oleh Saeed et al. (2013) yang menyebutkan bahwa terdapat hubungan positif antara pemberdayaan dengan komitmen profesionalkaryawan. Dilihat dari beberapa penelitian diatas maka dapat dirumuskan hipotesis penelitian sebagai berikut:

\section{$\mathrm{H}_{5}$ : Pemberdayaan berpengaruh positif terhadap komitmen professional}

Pemberdayaan akan memberikan dampak positif secara langsung terhadap komitmen professional karyawan (Jain et al., 2013). Topik tentang pemberdayaan 
terdiri dari bagaimana meningkatkan status, increased knowledge dan access kepada decision making sehingga dapat menurunkan stres kerja dan konflik pekerjaankeluarga yang di alami karyawan (Saeed et al, 2013). Penelitian Churiyah (2011) mendukung pernyataan ini, dimana peran pemberdayaan memediasi dengan positif dalam mengatasi stres kerja untuk meningkatkan komitmen profesional karyawan. Dilihat dari beberapa penelitian diatas maka dapat dirumuskan hipotesis penelitian sebagai berikut :

\section{$\mathbf{H}_{6}$ : Pemberdayaan memediasi pengaruh stres kerja terhadap komitmen professional}

Pemberdayaan merupakan wewenang untuk membuat keputusan dalam suatu area kegiatan tertentu dan juga pemberian wewenang kepada karyawan untuk merencanakan (planning), mengendalikan (controlling) dan membuat keputusan atas pekerjaan yang menjadi tanggung jawabnya tanpa harus mendapatkan otorisasi secara eksplisit dari atasannya (Popov et al, 2013). Churiyah (2011) dalam penelitiannya menunjukkan lima aspek pemberdayaan psikologis memediasi konflik pekerjaankeluarga terhadap komitmen profesional yang berkorelasi dengan motivasi intrinsik. Dilihat dari beberapa penelitian diatas maka dapat dirumuskan hipotesis penelitian sebagai berikut.

H7 $_{7}$ Pemberdayaan memediasi pengaruh negatif konflik pekerjaan-keluarga terhadap komitmen profesional. 


\section{METODE PENELITIAN}

Karya ilmiah ini menggunakan pendekataan asosiatif kausalitas (sebab akibat) yaitu pendekatan yang mampu menunjukkan hubungan antara dua variabel atau lebih (Sugiyono, 2013 :5). Lokasi penelitian pada PT. Bhineka Putra Perkasa yang berlokasi di Jl. Pulau Moyo No.5 Denpasar. Variabel yang digunakan dalam penelitian ini terdiri dari dua variabel eksogen yaitu stres kerja $\left(\mathrm{X}_{1}\right)$ dan konflik pekerjaan-keluarga $\left(\mathrm{X}_{2}\right)$. Variabel endogen yaitu komitmen profesional $(\mathrm{Y})$. Variabel mediasi (M) yaitu pemberdayaan. Jenis data kuantitatif dan kualitatif yang dipergunakan seperti data jumlah karyawan, jawaban responden terhadap kuisioner dan seperti sejarah perusahaan, struktur organisasi dan aktivitas perusahaan. Sumber data primer dan sekunder yang dipergunakan seperti observasi dan pemberian kuesioner kepada responden dan sejarah berdirinya perusahaan, struktur organisasi perusahaan, dan jumlah karyawan.

Jumlah sampel adalah karyawan di PT Bhineka Putra Perkasa Denpasar sebanyak 52 orang dari 142 populasi yang di klasifikasikan berdasarkan metode Proportionate Random Sampling (Sugiyono, 2013:124). Data yang dikumpulkan dalam penelitian ini menggunakan metode wawancara dan kuesioner melalui pertanyaan terstruktur yang telah dipersiapkan sebelumnya dan diberikan kepada responden. 


\section{Uji Validitas}

Syarat minimum sebuah instrumen dikatakan valid jika mempunyai korelasi positif dengan kriteria (skor total) $r \geq 0,3$ ". Adapun hasil uji validitas dapat dilihat pada Tabel 1.

Tabel 1. Asil Uji Validitas

\begin{tabular}{|c|c|c|c|c|}
\hline No & Variabel & Indikator & Korelasi & Keterangan \\
\hline \multirow{5}{*}{1} & \multirow{5}{*}{ Pemberdayaan (M) } & $\mathrm{X} 1.1$ & 0,811 & Valid \\
\hline & & X1.2 & 0,764 & Valid \\
\hline & & $\mathrm{X} 1.3$ & 0,846 & Valid \\
\hline & & $\mathrm{X} 1.4$ & 0,862 & Valid \\
\hline & & $\mathrm{X} 1.5$ & 0,812 & Valid \\
\hline \multirow{4}{*}{2} & \multirow{4}{*}{ Stres kerja $\left(\mathrm{X}_{1}\right)$} & $\mathrm{X} 1.1$ & 0,879 & Valid \\
\hline & & $\mathrm{X} 1.2$ & 0,883 & Valid \\
\hline & & $\mathrm{X} 1.3$ & 0,831 & Valid \\
\hline & & $\mathrm{X} 1.4$ & 0,870 & Valid \\
\hline \multirow{3}{*}{3} & \multirow{3}{*}{ Konflik pekerjaan-keluarga $\left(\mathrm{X}_{2}\right)$} & $\mathrm{X} 2.1$ & 0,849 & Valid \\
\hline & & $\mathrm{X} 2.2$ & 0,811 & Valid \\
\hline & & $\mathrm{X} 2.3$ & 0,847 & Valid \\
\hline \multirow{5}{*}{4} & \multirow{5}{*}{ Komitmen profesional $(\mathrm{Y})$} & Y.1 & 0,870 & Valid \\
\hline & & Y.2 & 0,820 & Valid \\
\hline & & Y.3 & 0,877 & Valid \\
\hline & & Y.4 & 0,844 & Valid \\
\hline & & Y.5 & 0,885 & Valid \\
\hline
\end{tabular}

Sumber : Data diolah, 2017

\section{Uji Reliabilitas}

Uji reabilitas menunjukan sejauh mana instrument dapat dipercaya dan diharapkan. Nilai suatu instrumen dikatakan reliabel bila nilai Cronbach's Alpha $\geq 0,6$. Berdasarkan analisis data dapat dilihat setiap variabel memiliki nilai Cronbach's Alpha $\geq 0,6$ yang berarti bebas terhadap uji reliabilitas. Adapun hasil uji reliabilitas dapat dilihat pada Tabel 2. 
Tabel 2. Hasil Uji Reliabilias

\begin{tabular}{|c|c|c|c|}
\hline \multirow[b]{2}{*}{ No } & \multirow[b]{2}{*}{ Variabel } & \multicolumn{2}{|c|}{ Cronbach's } \\
\hline & & & Keterangan \\
\hline 1 & Pemberdayaan (M) & 0,860 & Reliabel \\
\hline 2 & Stres kerja $\left(\mathrm{X}_{1}\right)$ & 0,886 & Reliabel \\
\hline 3 & Konflik pekerjaan-keluarga $\left(\mathrm{X}_{2}\right)$ & 0,776 & Reliabel \\
\hline 4 & Komitmen profesional (Y) & 0,909 & Reliabel \\
\hline
\end{tabular}

Sumber : Data diolah, 2017

\section{Teknik Analisis Data}

\section{Analisis Jalur (Path Analysis)}

Teknik analisis data adalah analisis jalur yang digambarkan model jalur hubungan kausal antar variabel penelitian dapat disajikan dalam Gambar 2.

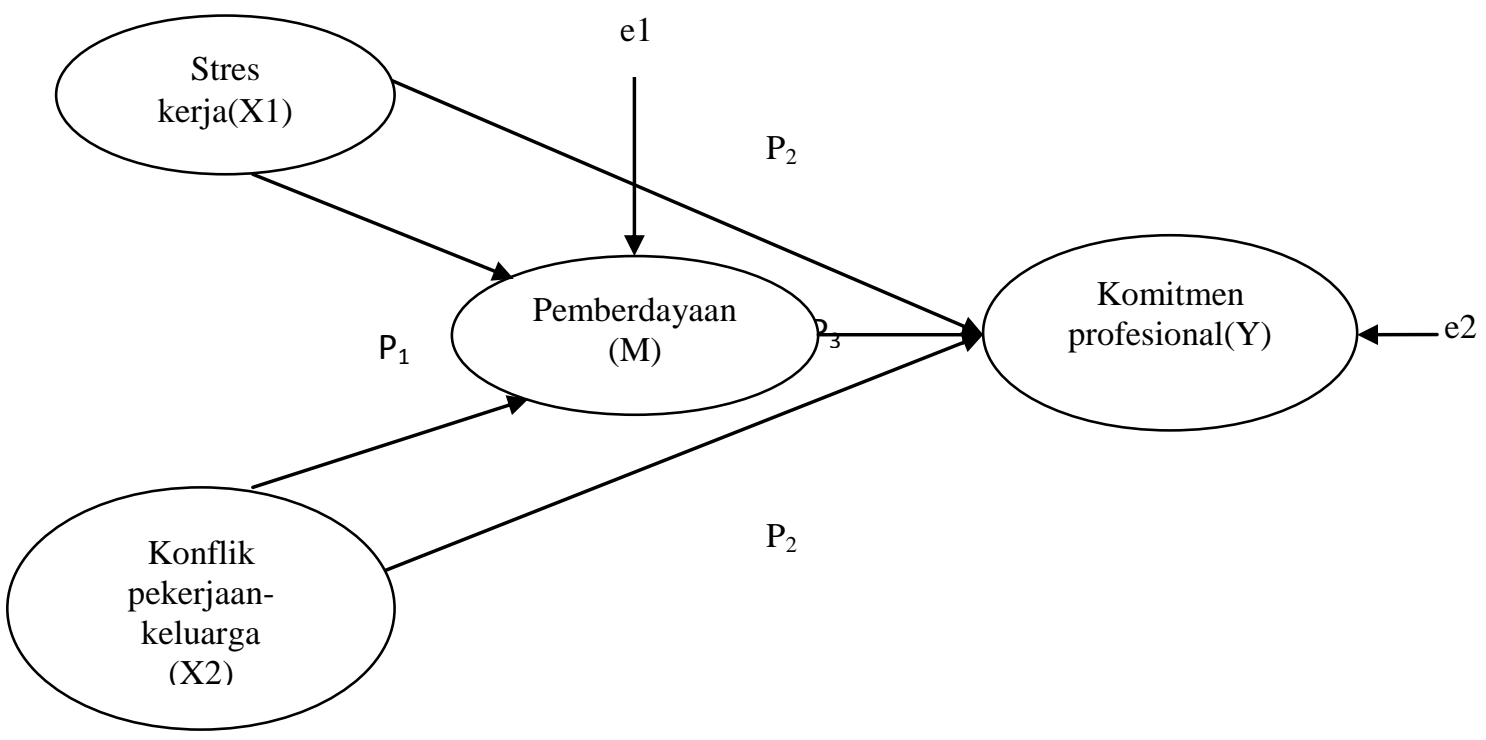

Gambar 2. Diagram Jalur Penelitian 


\section{HASIL DAN PEMBAHASAN}

\section{Hasil Analisis Jalur}

Dari model jalur yang dibentuk, terdapat dua persamaan struktural atau sistem persamaan simultan. Dari hasil pengolahan data dengan SPSS, model persamaan struktural atau sistem persamaan simultan untuk struktur pertama dan struktur kedua, menunjukkan hasil seperti pada Tabel 3 dan Tabel 4.

Tabel 3. Rekapitulasi Hasil Regresi Struktur 1

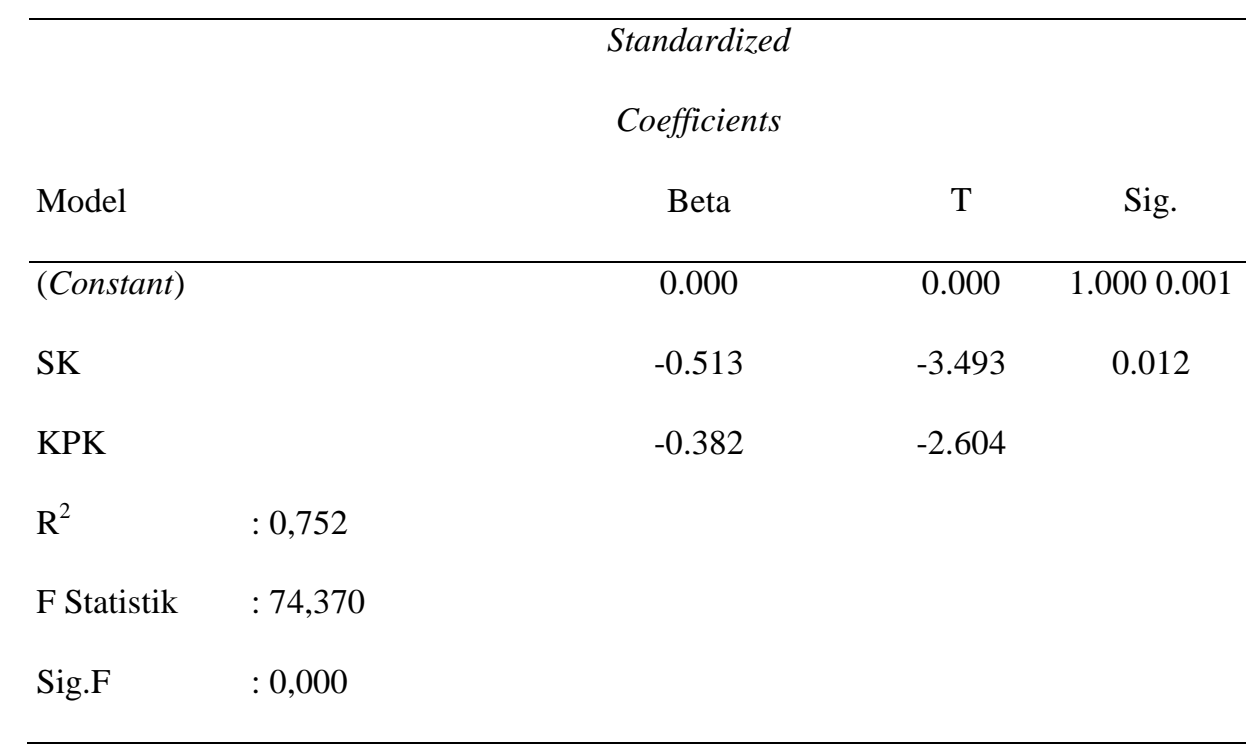

Sumber: Data diolah, 2017

Berdasarkan hasil pada Tabel 3, maka persamaan strukturalnya adalah sebagai berikut:

$$
M=-0,513 X_{1}-0,382 X_{2} e_{1}
$$

Stres kerja berpengaruh negatif terhadap pemberdayaan dengan nilai standardized sebesar $-0,513$ dan nilai sig t sebesar $0,001(<0,05)$, oleh karena nilai standardized coefficients beta sebesar -0,513 dengan nilai sig $\mathrm{t}=0,001$ maka 
I Gst Ngr Bgs Bimantara Kepakisan, Wayan Gede Supartha, dan I Gusti Ayu Manuati Dewi. Peran ...

$\mathrm{H}_{0}$ ditolak. Hal ini berarti variabel stres kerja berpengaruh negatif secara parsial terhadap pemberdayaan di PT Bhineka Putra Perkasa Denpasar.

Konflik pekerjaan-keluarga berpengaruh negatif terhadap pemberdayaan dengan nilai standardized coefficientsbeta sebesar $-0,382$ dan nilai sig t sebesar 0,012 $(<0,05)$, oleh karena nilai standardized coefficients beta sebesar $-0,382$ dengan nilai $\operatorname{sig} \mathrm{t}=0,012$ maka $\mathrm{H}_{0}$ ditolak. Hal ini berarti variabel konflik pekerjaan-keluarga berpengaruh negatif secara parsial terhadap pemberdayaan di PT Bhineka Putra Perkasa Denpasar.

Tabel 4. Rekapitulasi Hasil Regresi Struktur 2

\begin{tabular}{lcccc}
\hline & \multicolumn{3}{c}{ Standardized } \\
& Coefficients & & \\
Model & Beta & $\mathrm{T}$ & Sig. \\
\hline (Constant $)$ & & 0.000 & 0.000 & 1.0000 .035 \\
SK & & -0.233 & -2.168 & 0.022 \\
KPK & -0.242 & -2.364 & 0.000 \\
PM & $: 0,896$ & 0.520 & 5.566 & \\
$\mathrm{R}^{2}$ & $: 138,091$ & & & \\
F Statistik & $: 0,000$ & & & \\
Sig.F & & & & \\
Sumber: data diolah, 2017 & & & \\
\hline
\end{tabular}

Berdasarkan hasil pada Tabel 4, maka persamaan strukturalnya adalah sebagai berikut:

$$
Y=-0,233 X_{1}-0,242 X_{2}+0,520 M
$$


Stres kerja berpengaruh negatif terhadap komitmen profesional dengan nilai standardized coefficients beta sebesar -0,233 dan nilai sig t sebesar 0,035 $<0,05$, oleh karena nilai standardized coefficients beta sebesar $-0,233$ dengan nilai sig $\mathrm{t}=0,035$ maka $\mathrm{H}_{0}$ ditolak. Hal ini berarti variabel stres kerja berpengaruh negatif secara parsial terhadap komitmen profesional karyawan di PT Bhineka Putra Perkasa Denpasar.

Konflik pekerjaan-keluarga berpengaruh negatif terhadap komitmen profesional dengan nilai standardized coefficients beta sebesar -0,242 dan nilai sig $\mathrm{t}$ sebesar $0,022<0,05$, oleh karena nilai standardized coefficients beta sebesar -0,242 dengan nilai sig $\mathrm{t}=0,022$ maka $\mathrm{H}_{0}$ ditolak. Hal ini berarti variabel konflik pekerjaankeluarga berpengaruh negatif secara parsial terhadap komitmen profesional karyawan di PT Bhineka Putra Perkasa Denpasar.

Pemberdayaan berpengaruh positif signifikan terhadap komitmen profesional dengan nilai standardized coefficients beta sebesar 0,520 dan nilai sig t sebesar $0,000<0,05$, oleh karena nilai standardized coefficients beta sebesar 0,520 dengan nilai sig $\mathrm{t}=0,000$ maka $\mathrm{H}_{0}$ diterima. Hal ini berarti variabel pemberdayaan berpengaruh positif dan signifikan secara parsial terhadap komitmen profesional karyawan di PT Bhineka Putra Perkasa Denpasar.

Pengaruh variabel stress kerja $\left(\mathrm{X}_{1}\right)$ dan konflik pekerjaan-keluarga $\left(\mathrm{X}_{2}\right)$ terhadap komitmen profesional (Y) dengan mediasi pemberdayaan (M). Output hasil SPSS pengujian digambarkan dengan model diagram jalur seperti pada Gambar 3 berikut. 


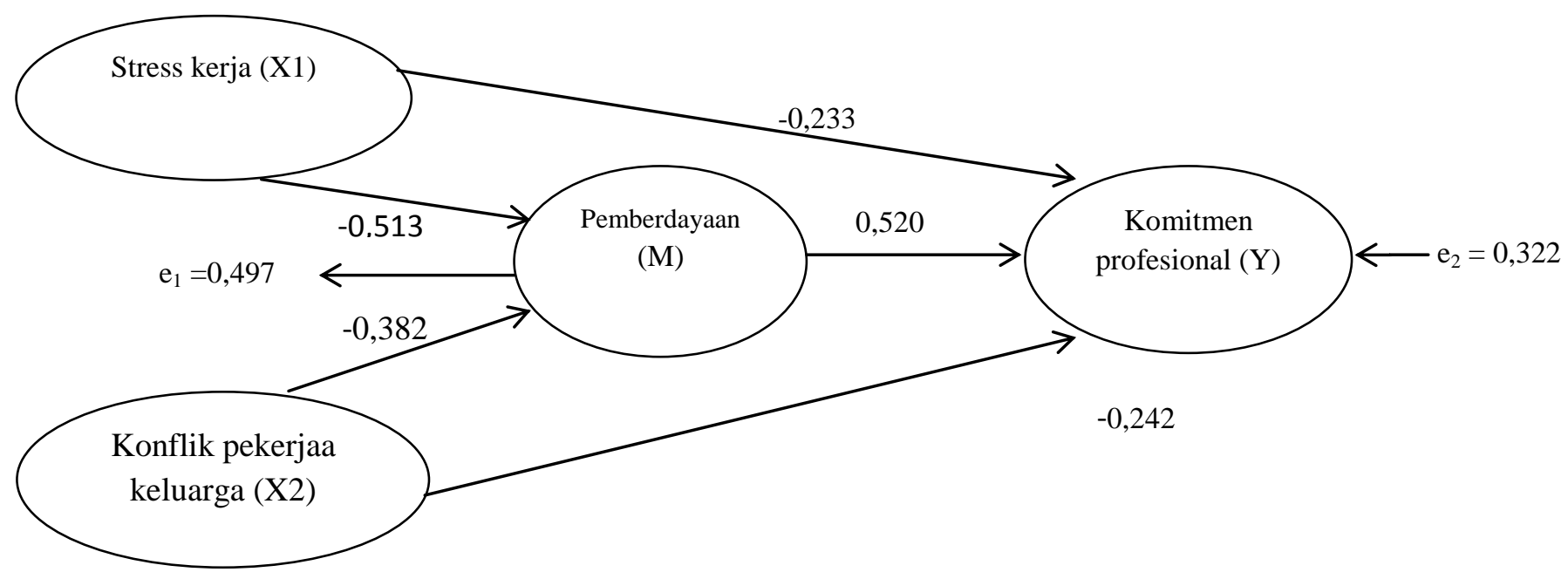

Gambar 3. Model Diagram Jalur Akhir

Gambar 3 menunjukkan koefisien jalur pengaruh stress kerja dan konflik pekerjaan-keluarga terhadap komitmen profesional setelah variabel pemberdayaan dimasukan ke dalam model bernilai 0,520 tidak bernilai 0 , yang berarti pemberdayaan memediasi pengaruh stress kerja dan konflik pekerjaan-keluarga terhadap komitmen professional karyawan di PT Bhineka Putra Perkasa.

\section{Uji Sobel}

Pengaruh variabel stress kerja $\left(\mathrm{X}_{1}\right)$ terhadap komitmen profesional $(\mathrm{Y})$ dengan mediasi pemberdayaan (M).

$$
\begin{aligned}
& S_{a b}=\frac{0,513 \cdot 0,520}{\sqrt{0,513^{2} 0,093^{2}+0,520^{2} 0,147^{2}+0,147^{2} 0,093^{2}}} \\
& S_{\mathrm{ab}}=2,927
\end{aligned}
$$

Hasil perhitungan menunjukkan perbandingan nilai $\mathrm{z}$ hitung sebesar $2,927>\mathrm{z}$ tabel sebesar 0,096, maka Ho ditolak dan Hi diterima. Artinya pemberdayaan 
memediasi pengaruh stress kerjaterhadap komitmen profesional karyawan di PT Bhineka Putra Perkasa.

Pengaruh variabel konflik pekerjaan-keluarga $\left(\mathrm{X}_{2}\right)$ terhadap komitmen profesional (Y) dengan mediasi pemberdayaan (M).

$$
\begin{aligned}
& S_{a b}=\frac{0,382 \cdot 0,520}{\sqrt{0,382^{2} 0,093^{2}+0,382^{2} 0,147^{2}+0,147^{2} 0,093^{2}}} \\
& S_{\mathrm{ab}}=2,362
\end{aligned}
$$

Hasil perhitungan menunjukkan perbandingan nilai $\mathrm{z}$ hitung sebesar 2,362 > z tabel sebesar 0,096, maka Ho ditolak dan Hi diterima. Artinya pemberdayaan memediasi pengaruh konflik pekerjaan-keluarga terhadap komitmen profesional karyawan di PT Bhineka Putra Perkasa

Menguji nilai koefisien determinasi $\left(\mathrm{R}^{2}\right)$

Hasil koefisien determinasi total dengan perhitungan sebagai berikut:

$$
\begin{aligned}
& \mathrm{R}_{\mathrm{m}}^{2} \quad=1-\left(\mathrm{Pe}_{1}\right)^{2}\left(\mathrm{Pe}_{2}\right)^{2} \\
& =1-(0,498)^{2}(0,322)^{2} \\
& =1-(0,248)(0,103) \\
& =1-0,025=0,975
\end{aligned}
$$

Nilai determinasi total sebesar 0,975 mempunyai arti bahwa sebesar 97,5\% variasi komitmen profesionaldipengaruhi oleh variabel stres kerja dan konflik pekerjaan-keluarga yang dimediasi oleh pemberdayaan, sedangkan sisanya sebesar 2,5 persen dijelaskan oleh faktor lain yang tidak dimasukkan ke dalam model.

\section{Pembahasan Hasil Penelitian}


Pengaruh stres kerja terhadap pemberdayaan karyawan.

Hasil uji parsial menunjukan bahwa stress kerja berpengaruh negatif terhadap pemberdayaan karyawan di PT Bhineka Putra Perkasa Denpasar. stress kerja yang di alami karyawan akan memberikan dampak negatif terhadap pemberdayaan karyawan.

Pengaruh konflik pekerjaan-keluarga terhadap pemberdayaan karyawan.

Hasil uji parsial menunjukan bahwa konflik pekerjaan-keluarga berpengaruh negatif terhadap pemberdayaan karyawan di PT Bhineka Putra Perkasa Denpasar. Terciptanya konflik pekerjaan-keluarga secara langsung akan meniadakan pemberdayaan karyawan di dala perusahaan.

Pengaruh stres kerjaterhadap komitmen profesional karyawan.

Hasil uji parsial menunjukan bahwa stress kerja berpengaruh negatif terhadap komitmen profesional karyawan di PT Bhineka Putra Perkasa Denpasar. Stress kerja yang di alami karyawan akan memberikan dampak negatif terhadap komitmen profesional karyawan.

Pengaruh konflik pekerjaan-keluarga terhadap komitmen profesional karyawan.

Hasil uji parsial menunjukan bahwa konflik pekerjaan-keluarga berpengaruh negatif terhadap komitmen profesional karyawan di PT Bhineka Putra Perkasa Denpasar. Konflik pekerjaan-keluarga yang dialami oleh karyawan memicu terjadinya penurunan pada sikap komitmen profesional karyawan dalam bekerja.

Pengaruh pemberdayaan terhadap komitmen profesional karyawan. 
Hasil uji parsial menunjukan bahwa pemberdayaan berpengaruh positif dan signifikan terhadap komitmen profesional karyawan di PT Bhineka Putra Perkasa Denpasar. Melakukan pemberdayaan menjadi suatu pekerjaan bagi manajemen agar terus berupaya menjaga kelangsungan perusahaan dengan turut serta memotivasi karyawan yang memberikan pengaruh positif pada komitmen profesional karyawan dalam bekerja.

\section{Pemberdayaan memediasi stres kerja terhadap komitmen profesional karyawan.}

Hasil uji parsial menunjukan bahwa pemberdayaan mampu memediasi pengaruh negatif stress kerja terhadap komitmen profesional karyawan di PT Bhineka Putra Perkasa Denpasar. Mempelajari tentang pemberdayaan akan memberikan dampak positif secara langsung terhadap komitmen profesional karyawan yang dapat menurunkan stres kerja yang di alami karyawan.

\section{Pemberdayaan memediasi konflik pekerjaan-keluarga terhadap komitmen profesional karyawan.}

Hasil uji parsial menunjukan bahwa pemberdayaan mampu memediasi pengaruh negatif konflik pekerjaan-keluarga terhadap komitmen profesional karyawan di PT Bhineka Putra Perkasa Denpasar. Pemberdayaan merupakan wewenang untuk membuat keputusan dalam suatu area kegiatan tertentu dan juga pemberian wewenang kepada karyawan untuk merencanakan (planning), mengendalikan (controlling) dan membuat keputusan atas pekerjaan yang menjadi 
tanggung jawabnya tanpa harus mendapatkan otorisasi secara eksplisit dari atasannya sehingga mampu menurunkan konflik pekerjaan-keluarga untuk menciptakan komitmen profesional karyawan.

\section{SIMPULAN DAN SARAN}

Berdasarkan pembahasan pada bab-bab sebelumnya, maka adapun hal-hal yang dapat disimpulkan yaitu, stress kerja berpengaruh negatif terhadap pemberdayaan karyawan di PT Bhineka Putra Perkasa. Stress kerja berpengaruh negatif terhadap pemberdayaan karyawan di PT Bhineka Putra Perkasa. Konflik pekerjaan-keluarga berpengaruh negatif terhadap pemberdayaan karyawan di PT Bhineka Putra Perkasa. Stress kerja berpengaruh negatif terhadap komitmen professional karyawan di PT Bhineka Putra Perkasa. Konflik pekerjaan-keluarga berpengaruh negatif terhadap komitmen profesional karyawan di PT Bhineka Putra Perkasa. Pemberdayaan memediasi pengaruh negatif stress kerja terhadap pemberdayaan karyawan di PT Bhineka Putra Perkasa. Pemberdayaan memediasi pengaruh negatif konflik pekerjaan-keluarga terhadap pemberdayaan karyawan di PT Bhineka Putra Perkasa.

Berdasarkan simpulan, saran-saran yang dapat diberikan bagi PT Bhineka Putra Perkasa sebagai perusahaan harus bertindak dengan integritas, melalui konsistensi dengan memilih dan menempatkan karyawannya disesuaikan dengan kemampuan dan pengetahuan yang dimilikinya untuk menghindari konflik kerja yang 
menimbulkan pekerjaan menjadi tidak dapat terselesaikan tepat pada waktunya. PT Bhineka Putra Perkasa Denpasar sebagai perusahaan harus bertindak tegas untuk menanggapi keluhan dari karyawan ini, dengan cara membina setiap karyawan memberikan pelatihan, pemahaman sehingga mempunyai rasa saling memiliki satu sama lainnya untuk menciptakan kerjasama yang baik sehingga menurunkan tingkat stress dalam bekerja. PT Bhineka Putra Perkasa Denpasar dalam membebankan pekerjaan kepada karyawan lebih mempertimbangkan waktu kerja yang diterapkan seperti mengurangi jam lembur, memberikan pekerjaan yang tidak bertumpuktumpuk kepada karyawan sehingga membutuhkan waktu ekstra untuk menyelesaikannya. Hal ini harus dilakukan untuk menghindari terjadinya keluhan dari karyawan sehingga karyawan memiliki kebahagiaan dengan keluarga untuk menghindari terjadinya konflik pekerjaan keluarga.

\section{REFERENSI}


I Gst Ngr Bgs Bimantara Kepakisan, Wayan Gede Supartha, dan I Gusti Ayu Manuati Dewi. Peran ...

Akintayo, D.I., 2010. Work-Family Role Conflict and Organizational Commitment Among Industrial Workers in Nigeria. Journal of Psychology and Counseling. 2(1): pp:1-8

Allen, N.J. and Meyer, J.P., 1997. Commitment in The Workplace Theory Research and Application. Califotnia: Sage Publications.

Arends, R. 1997. Classroom Instructional and Management. New York: McGraw Hill Comapanies.

Badjuri, A. 2009. Pengaruh Komitmen Organisasional dan Profesional Komitmen Terhadap Kepuasan Kerja dengan Motivasi Sebagai Variabel Intervening. Jurnal Kajian Akuntansi Ekonomi. 1(2): pp: 117-132

Bragger, J.D., Srednicki, O.R., Kutcher, E.J., Indovino, L., and Rosner, E., 2005. Work-family Culture, Work-family Conflict, Organizational Commitment, Job Satisfaction, and Organizational Citizenship Behavior (OCB) Among Teachers. Journal of Business and Psychology, 20(2): pp:303-324

Chasanah, Nur., 2008. Analisis Pengaruh Empowerment, Self Efficacy dan Budaya Organisasi Terhadap Kepuasan Kerja dalam Meningkatkan Kinerja Karyawan (Studi Empiris pada Karyawan PT Mayora Tbk Regional Jateng dan DIY). Studi Publikasi Tesis Ekonomi Universitas Diponegoro.

Churiyah, M., 2011. Pengaruh Konflik Peran, Kelelahan Emosional terhadap Kepuasan Kerja dan Komitmen Organisasi. Jurnal Ekonomi Bisnis. 16(2): pp:145-154

Febrianty, 2012. Pengaruh Role Conflict, Role Ambiguity and Work-Family Conflict terhadap Komitmen Organisasional (Studi Pada KAP di Sumatera Bagian Selatan). Jurnal Ekonomi dan Informasi Akuntansi. 2(3): pp:315-339

Fereshti, N.D., and Fatkhurohman, 2012. Reducing Role Conflict and Role Overload: The Case of Burnout. Jurnal Manajemen dan Bisnis, 1(2): pp:1-8

Greenberg, J., and Baron, R.A., 2003. Behaviour in Organizations, Understanding and Managing The Human Side of Work. Third Edition. Allin and Bacon. A Division of Schuster. Massachuscets 
Jain, A.K., Giga, S.I., and Cooper, C.L, 2013. Stress, Health and Well-Being: The Mediating Role of Employee and Organizational Commitment. International Journal of Environmental Research and Public Health. 2(3): pp: 4907-4924

Jawwad, A., and Hussain, M., 2012. The Impact of Work-Family Conflicts on Job Stress and Turnover-Organizational Commitment and Job Satisfaction as a Mediator. Journal Economic and Environmental Studies. 12(4): pp:363-372

Kreitner dan Kinicki. 2005. Perilaku Organisasi, Jakarta. Selemba empat

Khatibi, A. H. Asadi and M. Hamidi. 2009. The Relationship Between Job Stress and Organizational Commitment in National Olympic and Paralympic Academy. World Journal of Sport Sciences, 2 (4): h: 272-278

Khattak, M.A., Ul-ain and Iqbal, N., 2013. Impact of Role Ambiguity on Job Satisfaction, Mediating Role of Job Stress. International Journal of Academic Research in Accounting, Finance and Management Sciences. 3(3): pp: 28-39

Laeeque, S.H., 2014. Role of Work-Family Conflict in Job Burnout: Support from the Banking Sector of Pakistan. International Letters of Social and Humanistic Sciences, 4(1): pp: 1-12

Luthans, F., 2011, Perilaku Organisasi, Edisi kesepuluh, Penerbit Andi Offset

Mangkunegara, A.A. Anwar Prabu. 2011. Manajemen Sumber Daya Manusia Perusahaan. Bandung: PT. Remaja Rosdakarya

Murtiasri, E, 2006. Anteseden dan Konsekuensi Burnout pada Auditor: Pengembangan terhadap Role Stress Model. Jurnal Simposium Nasional. 3(1): pp: $1-27$

Ozbag, G.K., and Ceyhun, G.C., 2014. The Impact of Job Characteristics on Burnout; The Mediating Role of Work Family Conflict and the Moderating Role of Job Satisfaction. International Journal of Academic Research in Management. 3(3): h: 291-309

Popov, B., Miljanovic, M., Stojakovic, M., and Matanovic, J., 2013. Work Stressors, Distress, and Burnout: The Role of Coping Strategies. Journal Primenjena Psihologija, 6(4): pp: 355-370 
I Gst Ngr Bgs Bimantara Kepakisan, Wayan Gede Supartha, dan I Gusti Ayu Manuati Dewi. Peran ...

Rantika, R., 2010. Pengaruh Konflik Kerja-keluarga terhadap Komitmen Organisasional yang dimediasi oleh Kepuasan Kerja pada Profesi Perawat di Rumah Sakit Umum Daerah (RSUD) Dr. Moewardi Surakarta. Journal Published on Proceeding of Seminar Akbar Forum Manajemen Indonesia. 1(1): pp: $1-17$

Rivai, Veithzal. 2006. Kepemimpinan dan Perilaku Organisasi. Jakarta : PT. Raja Grapindo Persada.

Robbins, S. P., 2008. Teori organisasi, struktur, desain, dan aplikasi. (Alih Bahasa: Tim Indeks). New Jersey: Prentice Hall.

Saeed, R., Hashmi, A., Lodhi, R.N., Ahmad, M., Arshad, H.M.I., and Ahmad, M.A., 2013. The effect of Transformational Leadership on Organizational Commitment with a Mediating effect of Psychological Empowerment. Journal of Basic and Applied Scientific Research. 3(6): pp: 28-36

Shakeel, A., Farhan, A., and Shamyla, A., 2012. Job Burnout and Organizational Citizenship Behaviors: Mediating Role of Affective Commitment. Journal of Basic and Applied Scientific Research. 2(8): pp: 8120-8129

Siwi, T., 2005. Pengaruh Komitmen Profesi, Partisipasi Anggaran, dan Self Efficacy terhadap Konflik Peran (Studi Empiris pada Wanita Karis di Yogyakarta). Simposium Riset Ekonomi II.

Sugiyono. 2013. Metode Penelitian Bisnis. Bandung : CV.Alfabeta.

Suyana Utama, Made. 2009 “Buku Ajar Aplikasi Analisis Kuantitatif. Denpasar :Fakultas Ekonomi Universitas Udayana

Timangratuogi, W., 2012. Pengaruh Stress Kerja terhadap Kepuasan Kerja Karyawan bagian Sales/Penjualan PT. Indomobil Trada Nasional Cabang Pajajaran Bogor. Jurnal Publikasi Ekonomi Universitas Indonesia. 2(4): pp:1-10

Yustrianthe, R.H., 2008. Pengaruh Flexible Work Arragement, Terhadap Role Conflict, Role Overload, Reduced Personal Accomplishment, Job Satisfaction dan Intention to Stay. Jurnal Bisnis dan Akuntansi. 10(3): pp:127-128

Yusuf, Yusni Hervy. 2013. Pengaruh Tingkat Partisipasi Dalam Tim Kerja dan Kompetensi Terhadap Komitmen Organisasi Dengan Pemberdayaan Sebagai Variabel Pemediasi (Studi Kasus pada pada Dosen PTS di Banda Aceh). Jurnal Ekonomi Manajemen dan Bisnis. 1(1): pp:1-26 